\title{
Is HERV-K and HERV-W Expression Regulated by miR-155 in Kidney Transplant Patients with Human Cytomegalovirus Infection?
}

\author{
Massimiliano Bergallo ${ }^{a}$ Valentina Daprà ${ }^{a}$ Cristina Calvi ${ }^{a}$ Paola Montanaria \\ Ilaria Galliano ${ }^{a}$ Paolo Ravanini ${ }^{b}$ \\ ${ }^{a}$ Department of Public Health and Pediatric Sciences, University of Turin Medical School, Turin, Italy; \\ ${ }^{b}$ Laboratory of Molecular Virology, Maggiore della Carità Hospital, Novara, Italy
}

\section{Keywords}

Human endogenous retrovirus $\mathrm{K} \cdot$ Human endogenous

retrovirus $\mathrm{W} \cdot \mathrm{miR}-155 \cdot$ Human cytomegalovirus

\section{Abstract}

According to the latest update, 2,578 unique mature microRNAs (miRNAs) are currently annotated in the human genome and participate in the regulation of multiple events, such as cellular proliferation or apoptosis. A previous study analyzing global miRNA expression patterns in GH cells (high human endogenous retrovirus, HERV, K vs. low) showed that 2 miRNAs (miR-663 and miR-638) are differentially regulated and exhibit expression parallel to that of HERV-K. The aim of this study was to evaluate HERV-K and -W pol gene and miR155 expression in kidney transplant recipients and the possible relationship between them. The comparison between kidney transplant patients negative for human cytomegalovirus (HCMV) infection and positive patients showed a significant difference in terms of miR-155 expression ( $p=$ 0.0111). We demonstrated that HERV-K and -W pol gene expression was significantly higher in CMV-infected kidney transplant recipients versus those not infected as previously reported by our groups. Our correlation data suggest that miR-155 are not directly involved in regulating the HERV notwithstanding that we together observed increased expression of HERV-K and -W and diminished expression of miR155 in HCMV-infected human kidney transplant recipients.

ㄷ) 2018 S. Karger AG, Basel

\section{Introduction}

MicroRNAs (miRNAs) are a class of short-length double-strand genome-encoded RNAs that are produced to repress posttranscriptionally the expression of cellular mRNAs. The overall effect of a miRNA on a gene's protein expression depends on whether its transcript is a direct or indirect target of the miRNA; for example, when a miRNA targets a protein's repressors, that miRNA will indirectly upregulate that protein (the so-called repressor of a repressor effect) [1].

The repression mechanism is not clearly defined yet but most probably is achieved by the translation repression and by the deadenylation and consequent degradation of target mRNAs [2].

\section{KARGER}

() 2018 S. Karger AG, Basel

E-Mail karger@karger.com

www.karger.com/int
Massimiliano Bergallo

Department of Public Health and Pediatric Sciences

University of Turin Medical School

Piazza Polonia 94, IT-10136 Turin (Italy)

E-Mail massimiliano.bergallo@unito.it 
According to the latest update, 2,578 unique mature miRNAs are currently annotated in the human genome [3] and participate in the regulation of multiple events, such as cellular proliferation or apoptosis. For this reason, it is expected to find different and tightly regulated expression levels among the cellular miRNAs, depending on the cellular program [4].

The regulation of host cell processes is one of the key factors that viruses have developed in million years for their survival in the organism, upregulating the production of enzymes and proteins useful for viral replication and altering the signal events that are responsible for the immune response.

The herpesvirus family comprehends many viruses able to control and modulate host cell processes permitting the survival by a latency phase after primary infection. The herpesvirus family modulation of cellular events is so elaborated that it involves also cellular miRNAs, altering their expression [5]. Human cytomegalovirus (HCMV) is a member of the $\beta$-herpesvirus subfamily infecting $50-90 \%$ of the world population, responsible for congenital infection (with a higher prevalence in developing countries with $5 \%$ of births) and a major cause of morbidity in immunocompromised patients such as solid and bone marrow transplant recipients.

Human endogenous retrovirus (HERVs) and related retrotransposons constitute approximately $8 \%$ of the human genome [6]. Most HERVs are defective and generally not considered to be infectious [7], but are transmitted vertically. While they are known to be transcriptionally active during embryonic development, they are generally downregulated in adult human tissues by epigenetic mechanisms such as DNA methylation or chromatin modifications [8]. However, induction of HERV transcription is possible under certain circumstances, and may have a possible role in some pathological conditions.

A previous study analyzing global miRNA expression patterns in GH cells (high HERV-K vs. low) showed that 2 miRNAs (miR-663 and miR-638) are differentially regulated and exhibit expression parallel to that of HERV-K [9]. Several miRNAs, and especially miR-155, play an essential role in both the innate and adaptative immune response. Tili et al. [10] demonstrated that resveratrol impairs the upregulation of miR-155 by lipopolysaccharide in a miR-663-dependent manner. Hu et al. [11] identified many naturally occurring miR-155 target sites in HERV. Interaction between miR-155 and HERVs was further verified by a luciferase assay, and miR-155 was found to downregulate HERV expression [11]. Since the miR-155
Table 1. Main demographic and baseline characteristics of the study population

\begin{tabular}{ll}
\hline Patients, $n$ & 31 \\
Gender (male/female), $n$ & $22 / 9$ \\
Age (range), years & $59(26-67)$ \\
CMV D/R serostatus, n (\%) & $1(3)$ \\
$\quad$ D-/R+ & $30(97)$ \\
$\quad$ D+/R+ & \\
Induction immunosuppressive therapy, $n(\%)$ & $31(100)$ \\
$\quad$ Basiliximab & \\
Maintenance immunosuppression, $\mathrm{n}(\%)$ & $20(64.5)$ \\
$\quad$ CNI-based (CSA, TAC) & $6(19.4)$ \\
$\quad$ TAC, MMF, steroid & $5(16.1)$ \\
$\quad$ TAC, steroid & \\
$\quad$ CSA, MMF, steroid &
\end{tabular}

TAC, tacrolimus; CNI, calcineurin inhibitor; MMF, mycophenolate mofetil; CSA, cyclosporine A.

is regulated in a miR-663-dependent manner, we decided to evaluate HERV-K and -W pol gene and miR-155 expression in kidney transplant recipients and the possible relationship between them.

\section{Material and Methods}

Study Population

Thirty-one CMV seropositive kidney transplant patients (22/9 $\mathrm{M} / \mathrm{F}$, mean age $59 \pm 11.7$ years) afferent to Ospedale Maggiore della Carità (Novara, Northern Italy), from 1 to 8 years after transplantation (serological status $1 \mathrm{D}-/ \mathrm{R}+, 30 \mathrm{D}+/ \mathrm{R}+$ ) were enrolled. Informed consent was obtained from all individual participants included in the study. The immunosuppressive treatment was based of tacrolimus and mycophenolate mofetil and ganciclovir in the presence of cytomegalovirus (CMV) infection (Table 1). All procedures performed in studies involving human participants were in accordance with the ethical standards of the University of Turin research committee and with the 1964 Helsinki declaration and its later amendments or comparable ethical standards. At the moment of the study 20 transplanted patients were positive to human CMV (HCMV) infection and 11 were negative.

\section{Test Design}

Primer design was obtained using Primer express 3.0 (Life Technologies, Carlsbad, CA, USA). Forward primer and minor groove binder (MGB) probe were specific for miR-155 and RNU43 (calibrator for miR-155 quantification) detection. The primers and probe are listed in Table 2.

\section{DNA Extraction}

DNA extraction was performed starting from $1 \mathrm{~mL}$ of serum sample, to which $10 \mu \mathrm{L}$ of CPE-DNA (Q-CMV Real Time Complete Kit, ELITech Group, Puteaux, France) were added, followed by an extraction step using automatic extractor easyMAG (Bio-
Bergallo/Daprà/Calvi/Montanari/ Galliano/Ravanini 
Table 2. Primers and probes list (all the sequences are reported in 5'-3' direction)

\begin{tabular}{ll}
\hline Target & RNU43 \\
\hline $\begin{array}{l}\text { Sequence } \\
\text { Stem loop primer }\end{array}$ & GAACUUAUUGACGGGCGGACAGAAACUGUGUGCUGAUUGUCACGUUCUGAUU \\
$\begin{array}{l}\text { Forward } \\
\text { Probe minor groove binder family }\end{array}$ & $\begin{array}{l}\text { TGACTCTGGTGCAGGGTCCGAGGTATTCGCACCAGAGCCAATCAG } \\
\text { TGTGGCTGATTGTCA }\end{array}$ \\
\hline Target & miR-155 \\
\hline Sequence & UUAAUGCUAAUCGUGAUAGGGGU \\
Stem loop primer & GGCTCTGGTGCAGGGTCCGAGGTATTCGCACCAGAGCCACCCCT \\
Forward & CGCAGTTAATGCTAATCGTGATA \\
Probe minor groove binder family & GGGGTGGCTCTGG \\
Universal reverse primer & TGCAGGGTCCGAGGTATTC \\
\hline
\end{tabular}

mérieux, Marcy-l'Etoile, France), according to the manufacturer's instruction. The DNA extracted was eluted in a $25-\mu \mathrm{L}$ final elution volume.

\section{HCMV Real-Time PCR}

Five microliters of elute DNA were added to $20 \mu \mathrm{L}$ of amplification mix (Q-CMV Real Time Complete Kit, ELITech Group, Puteaux, France), following the manufacturer's instructions, and amplified with the following thermal profile: $50^{\circ} \mathrm{C}$ for $2 \mathrm{~min}, 95^{\circ} \mathrm{C}$ for $10 \mathrm{~min}, 45 \mathrm{cycles}$ of $95^{\circ} \mathrm{C}$ for $15 \mathrm{~min}, 60^{\circ} \mathrm{C}$ for $1 \mathrm{~min}$. The viral quantification was reported as copiesper milliliter following the manufacturer's instructions; the inferior detection limit was set as 110 copies/mL.

\section{RNA Extraction}

RNA extraction was performed according to the RNAzol protocol modified by Bergallo et al. [12] and starting from $400 \mu \mathrm{L}$ of thawed serum samples.

\section{miR-155 Reverse Transcription}

Reverse transcription (starting from 500 ng of total RNA) was performed with a Gene Amp RNA PCR kit (Life Technologies, Carlsbad, CA, USA) including some modifications: 50 U of MMLV RT, 1 mM dNTPs, 5 mM MgCl , 1 U RNase Inhibitor, $1 \times$ PCR buffer II and $0.5 \mu \mathrm{g}$ of miR-155 stem loop primer. The reaction was carried out in 3 steps: an initial incubation at $16^{\circ} \mathrm{C}$ for $30 \mathrm{~min}$, a further one at $42^{\circ} \mathrm{C}$ for $60 \mathrm{~min}$ and a final incubation at $99^{\circ} \mathrm{C}$ for $5 \mathrm{~min}$.

\section{RNA Quality and Integrity Evaluation}

RNA purity and concentration were evaluated by spectrophotometry using NanoDrop ND-2000 (Thermo Fisher Scientific, Wilmington, DE, USA). 260/230 and 260/280 absorbance ratios were used to assess the presence of contaminants: peptides, phenols, aromatic compounds, or carbohydrates and proteins.

miR-155 Expression Measurement by Real-Time MGB PCR

After the reverse transcription step, an asymmetric PCR using $300 \mathrm{nM}$ of specific forward primer (Table 1), $0.1 \mathrm{U}$ of GoTaq ${ }^{\circledR} \mathrm{Hot}$ Start polymerase (Promega, Bergamo, Italy), $4 \mu \mathrm{L}$ of $5 \times$ Colorless

HERV-K and HERV-W Expression and miR-155 in Kidney Transplant Patients
GoTaq ${ }^{\circledR}$ Flexi Buffer and $2 \mu \mathrm{L}$ of cDNA, obtaining a final volume of $20 \mu \mathrm{L}$, was performed. The thermal profile was the following: $95^{\circ} \mathrm{C}$ for $2 \mathrm{~min}, 30$ cycles of $94^{\circ} \mathrm{C}$ for $15 \mathrm{~min}, 55^{\circ} \mathrm{C}$ for $30 \mathrm{~min}$ and $72^{\circ} \mathrm{C}$ for $20 \mathrm{~min}$.

Five microliters of enriched cDNA were added to $35 \mu \mathrm{L}$ of reaction mix containing $800 \mathrm{nM}$ of forward primer, 1,000 $\mathrm{nM}$ of universal reverse primer, $200 \mathrm{nM}$ of MGB probe and $1 \times$ TaqMan Universal PCR Master Mix (P/N: 4324018 Life Technologies, Carlsbad, CA, USA) in a final volume of $40 \mu \mathrm{L}$. The amplifications were performed on an ABI 7500 real-time PCR system (Life Technologies, Carlsbad, CA, USA) in a 96 -well plate at $95^{\circ} \mathrm{C}$ for $10 \mathrm{~min}$, followed by $40 \mathrm{cycles}$ of $95^{\circ} \mathrm{C}$ for $15 \mathrm{~s}$ and $60^{\circ} \mathrm{C}$ for $1 \mathrm{~min}$. Each sample was run in triplicate.

The level of miR-155 expression was measured using the $\mathrm{Cq}$ (cycle quantification) value, the fractional cycle number at which the fluorescence of each sample passed a fixed threshold.

The $2^{-\Delta \mathrm{Cq}}$ method for relative quantification of gene expression was used to determine the level of miRNA expression. $\Delta \mathrm{Cq}$ was calculated by subtracting the Cq value of RNU43 RNA from the $\mathrm{Cq}$ value of the miR-155. RNU43 Cq values were obtained by a parallel asymmetric and real-time amplification with specific forward primer, probe and universal primer at the same conditions for miR-155 amplification. The $n$-fold change was calculated using the equation $n$-fold change $=2^{-\Delta \mathrm{Cq}}$. A negative control with $\mathrm{ddH}_{2} \mathrm{O}$ was included in the plate to avoid false-positive results.

\section{Quantitation of HERV-K and - W RNA by In-House}

Real-Time PCR

One microgram of RNA was used for cDNA synthesis by a Gene Amp RNA PCR kit (Life Technologies, TX, USA) according to the manufacturer's instruction. HERV-K and W expression was evaluated by relative quantitative relative real-time PCR on pol gene RNA, using glyceraldehyde-3-phosphate dehydrogenase (GAPDH) transcript as normalizer. Approximately $100 \mathrm{ng}$ cDNA were amplified in a $20-\mu \mathrm{L}$ total volume reaction containing $1 \times$ TaqMan Universal PCR Master Mix (Life Technologies, TX, USA), $900 \mathrm{nM}$ of specific HERV-K primers (KPOLF-5' CCACTGTAGAGCCTCCTAAACCC- $3^{\prime}$; KPOLR-5' ${ }^{\prime}$ TTGGTAGCGGCCACTGATTT- ${ }^{\prime}$ ) and probe (KPOLP-6FAM-CCCACACCGGTTTTTCTGTTTTCCAAGTTAA-TAMRA) or HERV- 
Table 3. Results of quantitative real-time PCR: viral load (copies/mL)

\begin{tabular}{lllr}
\hline Samples & $\begin{array}{l}\text { HCMV } \\
\text { negative }\end{array}$ & Samples & $\begin{array}{r}\text { HCMV } \\
\text { positive }\end{array}$ \\
\hline 1 & neg. & 12 & 117,100 \\
2 & neg. & 13 & 12,780 \\
3 & neg. & 14 & 2,490 \\
4 & neg. & 15 & 4,200 \\
5 & neg. & 16 & 60,500 \\
6 & neg. & 17 & 31,760 \\
7 & neg. & 18 & 3,960 \\
8 & neg. & 19 & 690,000 \\
9 & neg. & 20 & 4,630 \\
10 & neg. & 21 & 4,270 \\
11 & neg. & 22 & 1,540 \\
& & 23 & 960 \\
& & 24 & 600 \\
& & 25 & 430 \\
& & 26 & 110 \\
& & 27 & 250 \\
& & 28 & 420 \\
& & 29 & 1,560 \\
& & 30 & 470 \\
& & 31 & 840 \\
\hline
\end{tabular}

W primers (WPOLF-5'-ACMTGGAYKRTYTTRCCCCAA-3'; KPOLR-5' - GTAAATCATCCACMTAYYGAAGGAYMA$\left.3^{\prime}\right)$ and probe (WPOLP-6FAM-TYAGGGATAGCCCYCATCTRTTTGGYCAGGCA-TAMRA) or GAPDH-specific primers (GAPDHF-5'-CCAAGGTCATCCATGACAAC- $3^{\prime}$; GAPDHR-5' GTGGCAGTGATGGCATGGAC- $3^{\prime}$ ) and probe (GAPDH6FAM-TGGTATCGTGGAAGGA-3' MGB).

The amplifications were performed on an ABI 7500 Real-Time PCR system (Life Technologies, TX, USA) at $95^{\circ} \mathrm{C}$ for $10 \mathrm{~min}$, followed by 40 cycles of $95^{\circ} \mathrm{C}$ for $15 \mathrm{~s}$ and $60^{\circ} \mathrm{C}$ for $1 \mathrm{~min}$. Each sample was run in triplicate. Furthermore, in order to confirm that there was no DNA genomic contamination, a no-reverse-transcriptase control reaction in which no reverse transcriptase is added was performed using the same primers and probe described above.

Statistical Analysis

Mann-Whitney and Spearman tests were employed for the results analysis and $\mathrm{p}$ values calculated by GraphPAD Prism 5 (GraphPad Software, La Jolla, CA, USA).

\section{Results}

Thirty-one kidney transplant patients were enrolled in this study. In all the patients screening tests for the HCMV infection had previously been performed, based on the medical guidelines for transplant patient health care. Of

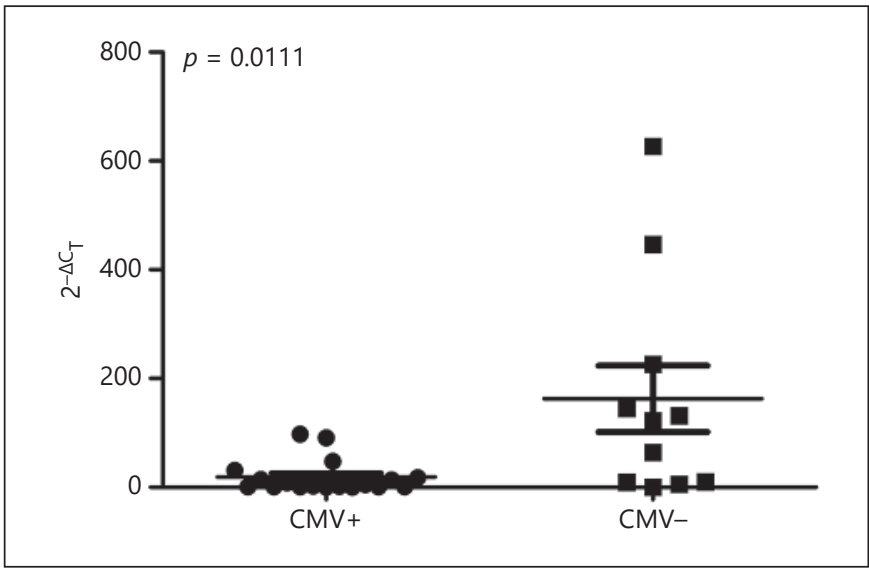

Fig. 1. miR-155 level comparison. miR-155 expression, normalized with RNU43 expression, in negative and positive CMV-infected kidney transplant recipients is represented. The $p$ value of the Mann-Whitney test is reported.

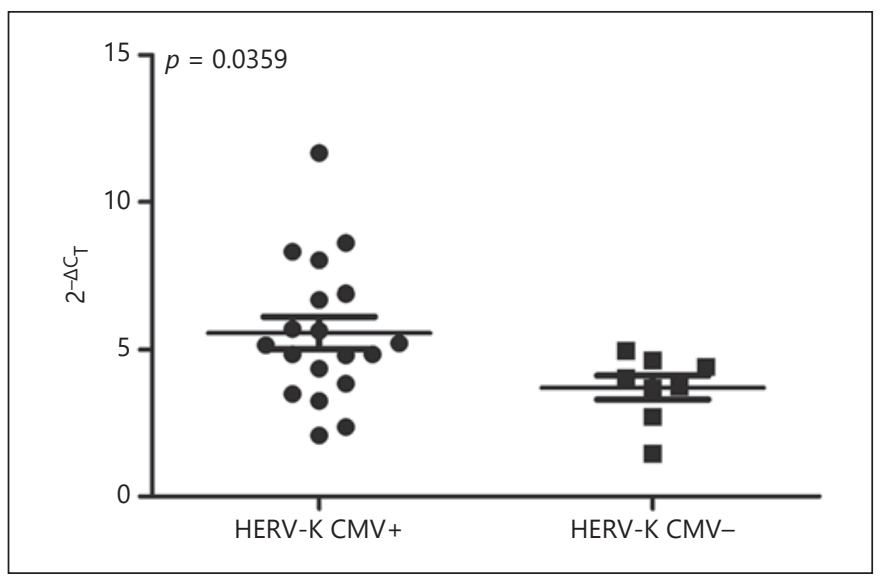

Fig. 2. HERV-K expression level comparison. HERV-K expression, normalized with GAPDH expression, in negative and positive CMV-infected kidney transplant recipients is represented. The $p$ value of the Mann-Whitney test is reported.

31 patients, 20 were positive for HCMV infection and 11 negative (Table 3 ).

Based on relative quantification, the miR-155 expression was compared among the groups previously described. As observable in Figure 1, the comparison between kidney transplant patients negative for HCMV infection and patients positive for it showed a significant difference in terms of miR-155 expression $(p=0.0111$; Fig. 1). 


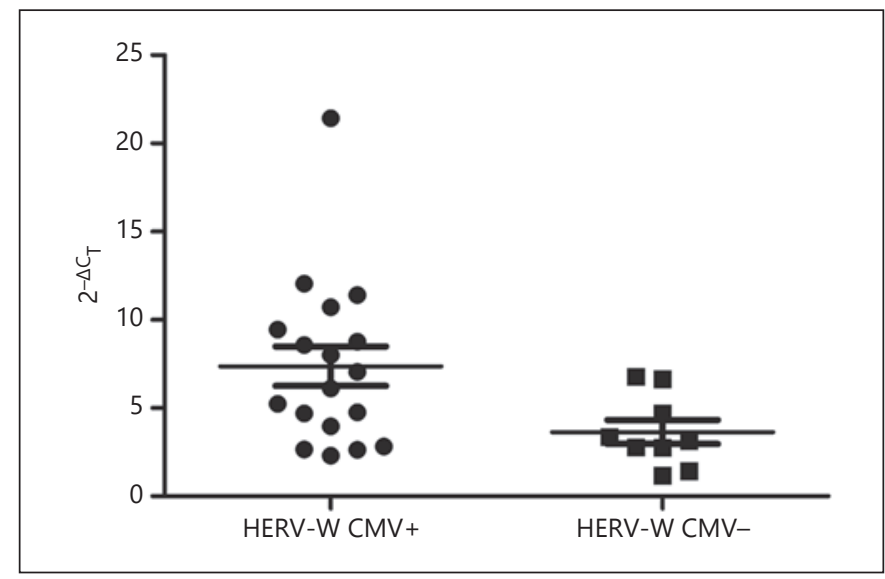

Fig. 3. HERV-W expression level comparison. HERV-W expression, normalized with GAPDH expression, in negative and positive CMV-infected kidney transplant recipients is represented. The $p$ value of the Mann-Whitney test is reported.

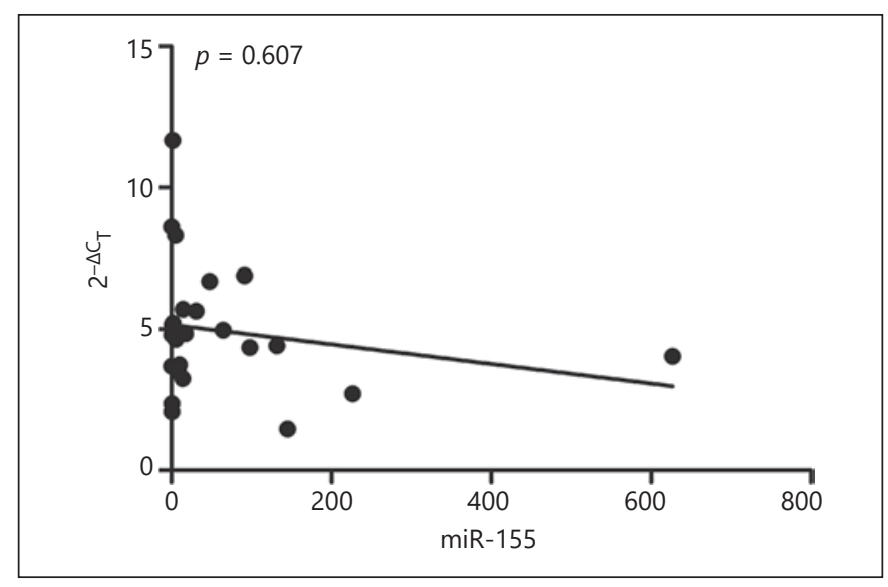

Fig. 4. Correlation analysis. Spearman's correlation analysis between miR-155 expression and HERV-K expression levels. $p=$ 0.607 was obtained comparing HERV-K pol gene expression with miR-155 expression.

Transcription levels of HERV-K and -W pol gene were analyzed by real-time quantitative RT-PCR (TaqMan system) using primers and probe located at the same $5^{\prime}$ part of the pol gene. We compared the HERV-K and -W expression levels in the two categories of transplant recipients (CMV infection vs. no infection). There was a significant difference from the mean values of the two groups as demonstrated by the Mann-Whitney U test and shown in Figures 2 and 3.

HERV-K and HERV-W Expression and miR-155 in Kidney Transplant Patients

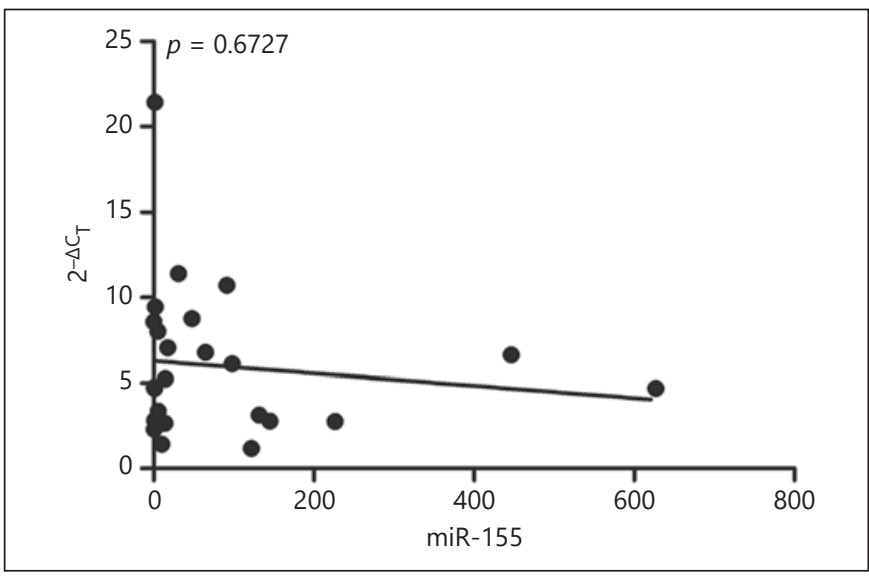

Fig. 5. Correlation analysis. Spearman's correlation analysis between miR-155 expression and HERV-W expression levels. $p=$ 0.6727 was obtained comparing HERV-W pol gene expression with miR-155 expression.

The miR-155 expression levels in sera, evaluated by stem loop real-time PCR analysis, was then plotted against HERV-K and -W relative quantification; however, Spearman's test demonstrated no correlation between miR-155 expression and HERV-K and -W expression levels (Fig. 4, 5).

Computational miRNA/mRNA target algorithms that utilize a number of biological parameters, including the requirement of seed sequence complementarity, remain the only source for rapid prediction of miRNA recognition sites harbored within the $3^{\prime}$-untranslated region of target mRNAs. Using a CLC Genomics Workbench (https://www.qiagenbioinformatics.com/support/resources/), the miR-155 target site was investigated in HERV. Using computational analysis, we identified 2 Homo sapiens miRNA-155-3p (hsa-miR-155-3p) target sites in the HERV env sequence (Fig. 6).

\section{Discussion}

Many biological processes are regulated by miRNA, such as development, cellular differentiation, proliferation, apoptosis, metabolism and immune response [13, 14]. A stem loop primer real-time PCR for miR-155 detection has been used as previously reported [15]. Results obtained showed a statistically significant reduction of miR-155 levels in patients with HCMV infection compared to patients without HCMV infection (Fig. 1) as previously reported by our groups [15]. This result is contro- 


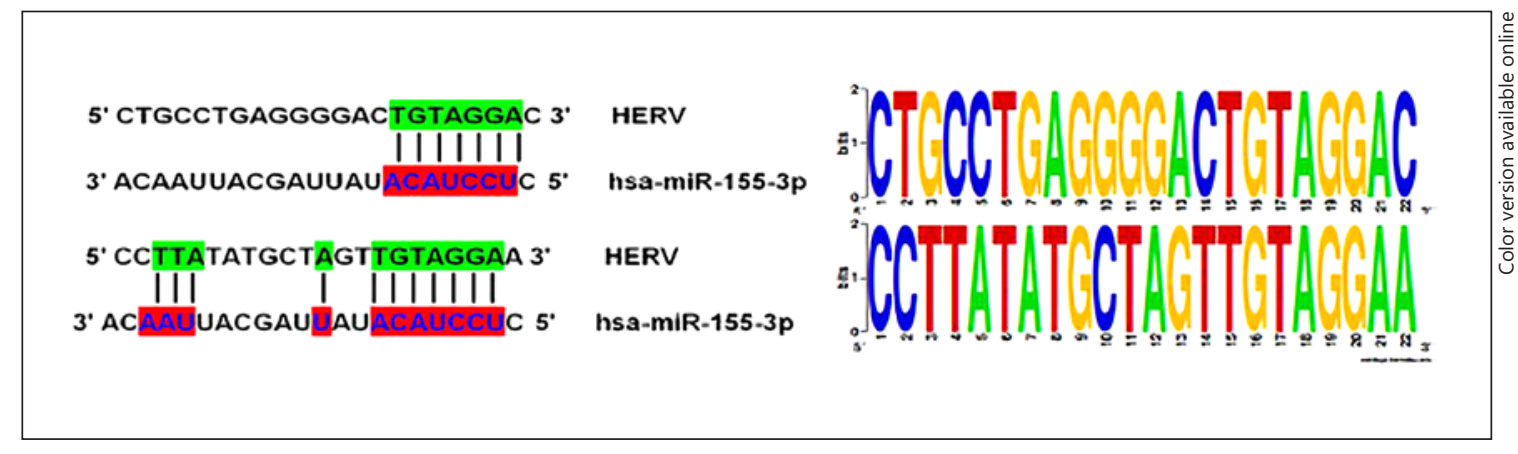

Fig. 6. Target site analysis of the miR-155 seed sequences in the human endogenous retrovirus.

versial as the results obtained by Wang et al. [16] showed a higher reduction of miR-155 levels days after infection, comparable to higher HCMV viral loads. To find out whether this discrepancy is casual or caused by in vivo events that offset the trend of progressive reduction, further studies are needed including a larger cohort of patients.

It is widely unclear how HERV gene expression is controlled or induced in pathological processes. We sought to define whether CMV infection in kidney transplant recipients may affect HERV expression. Our data suggest that CMV could facilitate HERV activation in vivo. We demonstrated that HERV-K and -W pol gene expression was significantly higher in CMV-infected kidney transplant recipients versus those not infected as previously reported by our groups [17]. Little is currently known about the induction of HERV-K expression, although CpG methylation status of the HERV promoter or their regulatory elements have been suggested to be crucial in the regulation of their activity $[18,19]$. Interestingly, Esteki-Zadeh et al. [20] reported that CMV causes a general hypomethylation by regulating DNA methyltransferase 1 and 3 expression in infected cells, which may also affect CpG methylation of the HML-2 promoter, or their regulatory elements, and thereby facilitate retroviral activation.

Bioinformatic analysis utilizing TargetScan 6.2 (http:// www.targetscan.org, release date June 2012) revealed that at least 4,174 putative human miR-155-5p mRNA targets exist, with a total of 918 conserved sites (i.e., between mouse and human) and 4,249 poorly conserved sites [2123 . It is important to note that the total number of miR1555 p putative binding sites (i.e. 5,167 ) is greater than the presumed number miR-155-5p mRNA targets since some of them harbor multiple miR-155 binding sites [24]. Therefore, mRNA target validation remains a critical step in defining the functions of individual miRNAs. Recently, Neilsen et al. [25] assembled a comprehensive list of miR$155-5 \mathrm{p} / \mathrm{mRNA}$ targets from the literature that were experimentally authenticated by both the demonstration of endogenous transcript regulation by miR-155-5p and validation of the miR-155-5p seed sequence through a reporter assay. This list was comprised of 140 genes and includes regulatory proteins for myelopoiesis and leukemogenesis (AICDA, ETS1, JARID2, SPI1, etc.), inflammation (BACH1, FADD, IKBKE, INPP5D, MYD88, RIPK1, SPI1, SOCS, etc.) and known tumor suppressors (C/EBP $\beta$, IL17RB, PCCD4, TCF12, ZNF652, etc.) [24]. Given that miR-155-5p plays important roles in many biological pathways, more investigation is needed to further define the in vivo mRNA targets of this miRNA. Notably, increased levels of ERV transcripts have been observed in individuals with virus infections [17] and those with autoimmune diseases [26], and miR-155 is involved in these pathological processes [27]. The significance of these findings is that miR-155 exerts its regulation by limiting overproduction of HERV during viral infection and by helping to stimulate innate immunity. Unfortunately, our correlation data suggest that miR-155 are not directly involved in regulating the HERV notwithstanding that we together observed increased expression of HERV-K and $-\mathrm{W}$ and diminished expression of miR-155 in HCMV-infected human kidney transplant recipients.

The results of the present study demonstrated that mRNA expression of HERV-K and -W and miR-155 did not directly correlate; in this way we could not accept the hypothesis of a direct involvement of miR-155 in the modulation of HERV as recently supposed by $\mathrm{Hu}$ et al. [11]. Furthermore, further studies including other cohorts of pathology with miR-155 and HERV involvement such as neoplastic diseases are needed to investigate the role of miR-155 in the cross-activations of HERVs.
28

Intervirology 2018;61:23-29 DOI: $10.1159 / 000490057$
Bergallo/Daprà/Calvi/Montanari/ Galliano/Ravanini 


\section{Ethics Statement}

All procedures performed in studies involving human participants were in accordance with the ethical standards of the University of Turin research committee and with the 1964 Helsinki declaration and its later amendments or comparable ethical standards. Informed consent was obtained from all individual participants included in the study.

\section{Disclosure Statement}

The authors declare that they have no conflict of interest.

\section{Funding Sources}

This study was funded by the University of Turin (BERM_ RIC_LOC_15_06).

\section{References}

1 Drury RE, O'Connor D, Pollard AJ: The clinical application of microRNAs in infectious disease. Front Immunol 2017;8:1182.

2 Huntzinger E, Izaurralde E: Gene silencing by microRNAs: contributions of translational repression and mRNA decay. Nat Rev Genet 2011;12:99-110.

3 Maudet C, Mano M, Eulalio A: MicroRNAs in the interaction between host and bacterial pathogens. FEBS Lett 2014;588:4140-4147.

4 Winter J, Jung S, Keller S, Gregory RI, Diederichs S: Many roads to maturity: microRNA biogenesis pathways and their regulation. Nat Cell Biol 2009;11:228-234.

5 Dhuruvasan K, Sivasubramanian G, Pellett PE: Roles of host and viral microRNAs in human cytomegalovirus biology. Virus Res 2011;157:180-192.

6 Bannert N, Kurth R: Retroelements and the human genome: new perspectives on an old relation. Proc Natl Acad Sci USA 2004;101: 14572-14579.

7 Flockerzi A, Burkhardt S, Schempp W, Meese E, Mayer J: Human endogenous retrovirus HERV-K14 families: status, variants, evolution, and mobilization of other cellular sequences. J Virol 2005;79:2941-2949.

8 Santoni FA, Guerra J, Luban J: HERV-H RNA is abundant in human embryonic stem cells and a precise marker for pluripotency. Retrovirology 2012;9:111.

9 Kraus B, Monk B, Sliva K, Schnierle BS: Expression of human endogenous retrovirus- $\mathrm{K}$ coincides with that of micro-RNA-663 and -638 in germ-cell tumor cells. Anticancer Res 2012;32:4797-4804.

10 Tili E, Michaille JJ, Adair B, Alder H, Limagne E, Taccioli C, Ferracin M, Delmas D, Latruffe $\mathrm{N}$, Croce CM: Resveratrol decreases the levels of miR-155 by upregulating miR-663, a microRNA targeting JunB and JunD. Carcinogenesis 2010;31:1561-1566.
11 Hu X, Zhu W, Chen S, Liu Y, Sun Z, Geng T, Wang X, Gao B, Song C, Qin A, Cui H: Expression of the env gene from the avian endogenous retrovirus ALVE and regulation by miR-155. Arch Virol 2016;161:1623-1632.

12 Bergallo M, Gambarino S, Martino S, Montin D, Montanari P, Galliano I, Tovo PA: Comparison of two available RNA extraction protocols for microRNA amplification in serum samples. J Clin Lab Anal 2016;30:277-283.

13 Bueno MJ, Perez de Castro I, Malumbres M: Control of cell proliferation pathways by microRNAs. Cell Cycle 2008;7:3143-3148.

14 O'Connell RM, Rao DS, Chaudhuri AA, Baltimore D: Physiological and pathological roles for microRNAs in the immune system. Nat Rev Immunol 2010;10:111-122.

15 Bergallo M, Gambarino S, Montanari P, Daprà V, Rassu M, Galliano I, Ravanini P: miR-155 expression is downregulated in kidney transplant patients with human cytomegalovirus infection. Transpl Immunol 2017; 43-44:60-63.

16 Wang FZ, Weber F, Croce C, Liu CG, Liao X, Pellett PE: Human cytomegalovirus infection alters the expression of cellular microRNA species that affect its replication. J Virol 2008; 82:9065-9074.

17 Bergallo M, Galliano I, Montanari P, Gambarino S, Mareschi K, Ferro F, Fagioli F, Tovo PA, Ravanini P: CMV induces HERV-K and HERV-W expression in kidney transplant recipients. J Clin Virol 2015;68:28-31.

18 Lavie L, Kitova M, Maldener E, Meese E, Mayer J: CpG methylation directly regulates transcriptional activity of the human endogenous retrovirus family HERV-K (HML-2). J Virol 2005;79:876-883

19 Stengel S, Fiebig U, Kurth R, Denner J: Regulation of human endogenous retrovirus-K expression in melanomas by $\mathrm{CpG}$ methylation. Genes Chromosomes Cancer 2010;49:401411.
20 Esteki-Zadeh A, Karimi M, Straat K, Ammerpohl O, Zeitelhofer M, Jagodic M, MehrabMohseni M, Sjoholm L, Rahbar A, SoderbergNaucler C, Ekström TJ: Human cytomegalovirus infection is sensitive to the host cell DNA methylation state and alters global DNA methylation capacity. Epigenetics 2012;7: 585-593.

21 Lewis BP, Burge CB, Bartel DP: Conserved seed pairing, often flanked by adenosines, indicates that thousands of human genes are microRNA targets. Cell 2005;120:15-20.

22 Grimson A, Farh KK, Johnston WK, GarrettEngele P, Lim LP, Bartel DP: MicroRNA targeting specificity in mammals: determinants beyond seed pairing. Mol. Cell 2007;27:91105

23 Friedman RC, Farh KK, Burge CB, Bartel DP: Most mammalian mRNAs are conserved targets of microRNAs. Genome Res 2009;1:92105.

24 Elton TS, Selemon H, Elton SM, Parinandi NL: Regulation of the MIR-155 host gene in physiological and pathological processes. Gene 2013;10:1-12.

25 Neilsen PM, Noll JE, Mattiske S, Bracken CP, Gregory PA, Schulz RB, Lim SP, Kumar R, Suetani RJ, Goodall GJ, Callen DF: Mutant p53 drives invasion in breast tumors through upregulation of miR-155. Oncogene J 2013;32: 2992-3000.

26 Sasaki N, Ogawa Y, Inuma C, Tomaru U, Katsumata K, Otsuka N, Kasahara M, Yoshiki $\mathrm{T}$, Ishizu A: Human endogenous retrovirus- $\mathrm{R}$ Env glycoprotein as possible autoantigen in autoimmune disease. AIDS Res Hum Retrovir 2009;25:889-896.

27 Vigorito E, Kohlhaas S, Lu D, Leyland R: miR155: an ancient regulator of the immune system. Immunol Rev 2013;253:146-157. 